\title{
CAUSAS E IMPACTOS DA INSTABILIDADE POLÍTICA NA PERFOMANCE DO COMÉRCIO INTERNACIONAL
}

Thamires Stoffel, Vanessa Theis ${ }^{1}$ \& Dusan Schreiber

Universidade FEEVALE, Rio Grande do Sul, (Brasil)

\section{DETALHES DO ARTIGO}

\section{Histórico do Artigo:}

Recebido em: 09 de junho de 2018

Aceito: 30 de outubro de 2018

Disponível online: 01 de janeiro de 2019

Sistema de revisão "Double blind review"

Editor Científico

Ilan Avrichir

\author{
Palavras-chaves: \\ Instabilidade Política \\ Comércio Exterior \\ Globalização \\ Governos \\ Crise Política
}

\begin{abstract}
RESUMO
Esta pesquisa apresenta um estudo reflexivo acerca de possíveis causas e os impactos da instabilidade política no desempenho do comércio internacional. Em formato de ensaio teórico, este artigo baseia-se em revisão teórica de autores que discutem sobre a globalização e seus reflexos sobre os Estados, e sobre as especificidades que caracteriza a instabilidade política. Na sequência, com o intuito de evidenciar os elementos que foram identificados a partir da revisão teórica, foi realizado o estudo baseado em levantamento documental, que detalham as situações e contexto de países que passam ou passaram por instabilidade política recentemente: Tunísia, Ucrânia, Paraguai e Brasil, a fim de analisar os impactos que as instabilidades políticas causam no Comércio Internacional destes países.
\end{abstract}

\section{INTRODUÇÃO}

Uma publicação do National Bureau of Economic Research (1992) sugeriu que o crescimento econômico e a estabilidade política estão conectados. A estabilidade política governamental é considerada, pela maioria dos pesquisadores do tema, como fator determinante para investimentos, principalmente quando os investimentos são oriundos de companhias estrangeiras (Moura, et. al, 2011). Nas últimas décadas, foi possível observar a relevância do conhecimento das políticas públicas contemporâneas, assim como das instituições, regras e modelos que regem sua decisão, elaboração, implementação e avaliação (Souza, 2009). Nessa perspectiva, é possível afirmar que, atualmente, as condições políticas representam o critério determinante e primordial do processo decisório de organizações internacionais, para alocar recursos e operacionalizar relações comerciais com outros países.

A incerteza política, associada a um ambiente de instabilidade, pode reduzir o investimento e o rumo do desenvolvimento econômico. Por outro lado, o mau desempenho econômico pode levar um governo à derrocada e, consequentemente, à instabilidade política no país. A instabilidade política em muitos países vem ganhando notoriedade na mídia nacional e internacional. Grandes crises políticas vêm atraindo bastante atenção internacional, sendo possível citarem-se algumas crises políticas que tiveram forte impacto, como a Primavera Árabe, a crise política no Paraguai, a recente saída do Reino Unido da União Europeia, a crise política na Ucrânia, além da atual e mais recente crise política e econômica brasileira (Souza, 2009).

A Primavera Árabe designa a onda de manifestações ocorridas no Oriente Médio e norte do continente africano em que a população foi às ruas para derrubar ditadores e reivindicar melhores condições sociais de vida. A crise política no Paraguai, na qual houve o processo de impedimento do então presidente Fernando Lugo, resultou em instabilidade política relevante e resultou na suspensão temporária do Paraguai de sua associação, como 
membro, dos blocos do Mercosul e da Unasul. A recente saída do Reino Unido da União Europeia, foi uma escolha de $52 \%$ dos britânicos que foram às urnas para votar por permanecer no bloco ou abandoná-lo e a crise política da Ucrânia teve início frente às manifestações em torno do parlamento do país, motivado pela não assinatura de um tratado de livre comércio com a União Europeia, processo mediado pela interferência da Rússia, o que resultou em uma tensão político-social entre ambos os países. Por fim, a atual crise política e econômica do Brasil, que culminou no processo de impeachment da Presidente da República, com destaque para a consolidação e institucionalização do combate à corrupção no país (Frizzera, 2013; G1, 2016; El País, 2014; BBC News, 2016; Valor Econômico, 2016).

Em linhas gerais, foi possível constatar-se que a instabilidade política voltou com força nestas duas últimas décadas, decorrente de inúmeros motivos, dentre os quais destaca-se insatisfação da maioria da população com o governo, corrupção, golpe de Estado, falta ou ineficiência de políticas públicas sociais, mau desempenho da economia e condução do governo em desacordo com as expectativas dos eleitores. Nesse sentido, surge a seguinte questão de pesquisa: tal instabilidade política gera impacto na performance do comércio exterior nos países? Sendo assim, o objetivo geral deste artigo é abordar o impacto que as crises políticas geram no desempenho dos negócios internacionais, sabendose da importância de uma política estável no âmbito econômico internacional.

Para atender ao exposto, foi realizada uma pesquisa documental sobre quatro países que passam ou passaram por instabilidade política, sendo um país do continente africano, Tunísia, um país europeu, Ucrânia, e dois países do continente sulamericano, Paraguai e Brasil, países estes que tiveram bastante repercussão nos meios de comunicação e negócios, a fim de realizar uma análise quanto ao impacto que essas instabilidades políticas geram nos países. Sabe-se que a globalização transformou a forma de comércio e de governo, com a abertura de mercado, com o crescimento da força das organizações privadas, e toda essa mudança afetou a forma de governança e as políticas públicas e contexto econômico.

\section{REFERENCIAL TEÓRICO}

Nesta seção serão apresentados os conceitos teóricos e estudos que fundamentaram esta pesquisa. Com o objetivo de facilitar o entendimento do tema abordado, o referencial teórico foi subdividido em: O fenômeno da globalização e seu impacto sobre os Estados e Instabilidade Política.

\section{O Fenômeno da Globalização e seu Impacto Sobre os Estados}

Em conformidade com Mariano (2007), a globalização é um conceito que gera debates quanto ao seu significado e ao seu impacto. O autor defende que alguns pesquisadores analisam esses fenômenos a partir do aspecto material: fluxos de comércio, de capital e de pessoas, facilitados pelo avanço da tecnologia e da comunicação e, consequentemente, pela integração social. Neste cenário globalizado, o Estado-Nação ganha novos contornos e conceitos de soberania e legitimidade, uma vez que o Estado perde a capacidade de responder isoladamente aos desafios do sistema internacional, assim como a de prover bens e serviços à sua população sem contar com a cooperação internacional.

$\mathrm{Na}$ época do mercantilismo, os Estados absolutistas detinham todo o poder, governavam com a mão de ferro a tudo e a todos. As ideias liberais do livre comércio ainda não tinham surgido. A monarquia, sustentada pelos nobres e comerciantes, impunha as políticas econômicas desejadas, sem interferências internas ou externas. Porém, o fenômeno da globalização está deslocando, atualmente, o centro do poder, outrora nas mãos dos governos, para as grandes empresas transnacionais (Torres, 2006).

Coelho e Oliveira (2016) expõem que existe a defesa hiperglobista de que, no processo de globalização, os Estados tornaram-se reféns do referido fenômeno, dentro da perspectiva, social, econômica e ambiental, e as empresas e investidores passaram a nortear os rumos dos negócios independentemente dos governos. Nesse fenômeno de globalização, conforme Mariano (2007), os Estados, em vez de desaparecerem, ganham uma nova lógica de operação. Nesse ponto de vista, seu poder é limitado frente ao avanço das forças nacionais que estreitam a capacidade dos governos de controlarem os contatos entre as sociedades e que impulsionam essas relações transfronteiriças.

A existência de sistemas de comunicação em tempo real, de redes de transportes em escala mundial e de infraestrutura torna-se um sistema indispensável para a acelerada intensificação de 
Causas e Impactos da Instabilidade Política na Perfomance do Comércio Internacional

trocas comerciais internacionais. Portanto, não se pode negligenciar a importância das naturezas políticas que se revelam igualmente, ou mais, decisivas para a atual configuração do comércio internacional (Campos \& Canavezes, 2007).

A criação das Organizações Internacionais Intergovernamentais, como a Organização das Nações Unidas (ONU), Organização Mundial do Comércio (OMC), Fundo Monetário Internacional (FMI), ocorridas após a Segunda Guerra Mundial, desempenham um papel importante na construção das políticas públicas internacionais, na medida em que as relações das organizações com outros atores (Estados membros e os Estados que se colocam como alvo da ação dessas organizações) decidem diretrizes para a concepção de políticas públicas de comércio internacional (Fronzaglia, 2011).

Inúmeras podem ser as ações tomadas pelos poderes públicos na esfera econômica, como: compra e venda de moeda estrangeira; elevação ou redução dos tributos; ampliação do volume da moeda nacional na economia; edição de normas legais de remessa de lucros ao exterior, repressão ao poder econômico e da defesa do consumidor, emissão de títulos públicos no sistema financeiro que influenciarão consequentemente nos juros a serem pagos pelo Estado (Clark, 2008). Tais conjuntos de medidas são tomadas, em suma, para atender as necessidades sociais e individuais diante de um quadro de carência de meios. Lins (2013) destaca, que diversas decisões estratégicas, ligadas, principalmente, aos problemas ambientais em escala global ou ao envolvimento em blocos e parcerias regionais, como Nafta, Mercosul, Unasul, necessariamente requerem Estados nacionais fortes e economias poderosas e integradas aos níveis locais, nacionais e regionais.

\section{Instabilidade Política}

Segundo World Bank Group (2012), a instabilidade política é capilar, ou seja, atua, de forma negativa, nas três dimensões - política, social e econômica. Além de danos aos ativos e interrupções nos negócios, a instabilidade política pode levar a uma perda de rendimentos para investidores indiretamente afetados por ela, assim como outros investimentos podem sofrer perda de atração, ainda mais nos casos de projetos de turismo (World Bank Group, 2012). Preocupações referentes a empregabilidade, desigualdade social, aumento dos preços dos alimentos, regimes políticos não democráticos, segundo o World Bank Group
(2012), têm originado distúrbios civis e violência políticas, corroendo as relações sociais estabelecidas, confiança nas instituições e percepção de segurança pessoal, potencializando a interpretação de risco no contexto, sugerindo a sua reprodutibilidade, pois as mudanças no perfil de risco em um país podem ser facilmente transmitidas e consequentemente afetar a percepção de risco percebido pelas populações de outros países.

A instabilidade política é considerada por economistas como um mal-estar prejudicial para o desempenho da economia, gerando um ambiente de instabilidade sociopolítica, aumentando as taxas de riscos e a redução de investimentos (FMI, 2016). Instabilidade política e crescimento da economia estão interligados em diversos níveis. A incerteza associada à instabilidade política tem impacto direto no crescimento da economia devido ao abatimento do investimento de capital físico, perda de capital humano (por exemplo, a migração), à volatilidade das políticas fiscais e monetárias que levam à alta da inflação, assim como o desempenho econômico insatisfatório e os elevados graus de desigualdade social podem resultar em uma agitação social e política derivada das expectativas da população em relação ao futuro e à oportunidade econômica do país (Verdugo; Furceri \& Guillaume, 2013). De acordo com Pereira (2015), o que diferencia um governo eficiente de um governo ineficiente é o seu grau de estabilidade política.

Drazen (2000) sinaliza que a instabilidade política cria incerteza sobre o futuro retorno dos investimentos das empresas e dos agentes privados, o que consequentemente inibe a sociedade como um todo para acumular capital físico (Ahmed \& Pulok, 2013). Países em processo de modernização são instáveis, pois neles ocorrem uma mudança social rápida e rápida mobilização de novos grupos para a política em conjunção com o lento desenvolvimento das políticas públicas. Para a consolidação do modelo de economia em desenvolvimento, é essencial que as instituições assegurem a ordem pública ou a estabilidade política, bom funcionamento do mercado e perspectivas positivas de retorno econômico do investimento, de forma a estimular os empresários e investidores (Pereira, 2015).

Pessanha (2015) sinaliza que a corrupção também resulta em instabilidade política, uma vez que tal prática, enfraquece as instituições democráticas, sejam elas públicas ou privadas, reduzindo o 
desenvolvimento econômico, contribuindo para a alta da inflação e para o aumento das taxas de desemprego. Além disto, afasta os investimentos estrangeiros e nacionais, dificultando as atividades empresariais, causando, prejuízos para a economia e para a sociedade.

De acordo com Badillo (2007), os modos para governar com estabilidade política estão pontualmente relacionados com a capacidade de os poderes legislativo e executivo formarem acordos partidários e sancionar as iniciativas de lei que fazem parte da agenda do governo. Os autores Chasquetti (2001), Cheibub (2002) e Negretto (2004) citam que os governantes que forem capazes de formar coalizações majoritárias detêm uma taxa de fracasso baixa e aceitável.

O Banco Mundial possui um banco de dados e uma equipe de profissionais que analisa a eficiência do governo por meio da captura de percepções da qualidade dos serviços públicos e dos cíveis, do grau da sua independência por pressões políticas, da qualidade da formulação e implementação das políticas, da credibilidade e compromisso do governo perante tais políticas. Também analisa a qualidade regulatória, ou seja, avalia a percepção da população local e mídia especializada quanto a habilidade do governo em formular e implementar políticas sólidas e regulamentações que permitem promover o desenvolvimento do setor privado, além do acompanhamento de análise de índice de estabilidade política nos países.

Conforme o Banco Mundial (2012), tal análise é construída a partir de múltiplas fontes de dados, incluindo The Economist Intelligence Unit, The World Economic Forum e a The Political Risk Services, que apontam índices subjacentes que mostram a probabilidade de uma transferência desordenada do poder do governo, de conflitos armados, manifestações violentas, agitação social, tensões internacionais, terrorismo, conflitos étnicos, religiosos ou regionais. Esses três índices avaliam a partir das notas 2,5 e -2,5, onde o índice de 2,5 significa um governo estável e $-2,5$ um governo instável.

\section{METODOLOGIA}

Conforme Köche (2011), o conhecimento científico é um produto resultante da investigação científica e surge não apenas da necessidade de encontrar soluções para os problemas de ordem prática da vida diária, mas do desejo de fornecer explicações sistemáticas que possam ser testadas e criticadas por meio de provas empíricas e da discussão intersubjetiva. A pesquisa científica visa conhecer um ou mais aspectos de determinado assunto, tendo como produto alguma contribuição para o avanço do conhecimento humano. Uma das preocupações permanentes que motivam a pesquisa científica é de conhecer as coisas, os fatos, os acontecimentos e os fenômenos, para tentar estabelecer uma previsão do rumo dos acontecimentos que cercam o homem e controlá-los. Com esse controle, pode ele melhorar a sua posição no mundo e criar, através do uso da tecnologia, melhores condições para a vida humana (Köche, 2011).

Este trabalho é classificado como descritivo, que, conforme Köche (2011), constata e avalia relações à medida que varáveis se manifestem espontaneamente em fatos, situações e condições que já existem. No que concerne aos procedimentos adotados, no âmbito da formalização desta pesquisa científica, considerou-se o mais adequado, para o alcance do objetivo proposto, realizar o estudo bibliográfico (Vergara, 2016). Cervo e Bervian (2007) apontam que a pesquisa bibliográfica procura estudar um problema a partir de referências teóricas publicadas em documentos. A principal particularidade da pesquisa bibliográfica, reside no fato de permitir ao investigador a cobertura de uma gama de fenômenos muito mais ampla do que aquela que poderia pesquisar diretamente, principalmente quando o problema de pesquisa abarca dados muito dispersos (Gil, 2008).

Ainda sob o ponto de vista do procedimento, este trabalho apresenta pesquisa documental, que, de acordo com Marconi e Lakatos (2011), é a fonte de coleta de dados escrita ou não, constituindo-se em fonte primária ou secundária. Esta coleta de dados ocorreu a partir de dados de organizações internacionais como Banco Mundial, FMl e The Global Economy bem como relatórios técnicos de organizações governamentais e não governamentais, além de reportagens de jornais e revistas de imprensa especializada em temas como política e economia.

A pesquisa bibliográfica foi realizada em sites de periódicos como Scientific Eletronic Library Online (SciELO), Scopus, CAPES, Google Acadêmico e Scribd com base nos termos "Instabilidade Política", "Crise 
Causas e Impactos da Instabilidade Política na Perfomance do Comércio Internacional

Política" "Globalização e os Estados" e "Comércio Internacional". As consultas foram realizadas no período de agosto a setembro de 2016, e o estudo compreende bibliografias nacionais e internacionais. Também foram elaboradas pesquisas na internet com base em teses, dissertações e revisões de livros, além de pesquisa de noticiários em jornais e revistas eletrônicas de nível nacional e internacional.

Para a análise dos dados coletados, foi feita uma interpretação da relação entre o referencial teórico da globalização e da instabilidade política com o desempenho do comércio internacional no período antecedente à crise política, no período político e na performance pós-crise política, buscando delinear o impacto das crises e da instabilidade política no comércio internacional, a partir da aplicação da técnica de análise quantitativa e qualitativa.

\section{ANÁLISE E DISCUSSÃO DOS RESULTADOS}

\section{Tunísia}

O gesto desesperado de um jovem tunisiano, Mohamed Bouazizi, que ateou fogo em si mesmo na cidade de Sisi Bouzid quando os policiais impediram que ele vendesse vegetais em uma banca de rua sem permissão, desencadeou uma onda de protestos contra o desemprego na região (BBC, 2011). O protesto foi considerado um reflexo de frustração da população com a elite dominante e a ausência de liberdades políticas. Segundo a reportagem, o governo tunisiano diz que 23 pessoas morreram desde o início dos protestos. A revolução na Tunísia em 2011 - a primeira manifestação política que se espalhou e resultou na denominada Primavera Árabe - foi marcada pelo fim de mais de cinco décadas de leis autoritárias (Hinds, 2014).

Uma reportagem da BBC NEWS (2016) cita que as massificações dos protestos iniciaram em 2011, com o pedido de destituição do governo de Ben Ali.

De acordo com Chomiak (2014), para o The Washington Post, atualmente, a proliferação dos partidos políticos e a força extraordinária da sociedade civil definem a política da Tunísia após a revolução de 2011, que mostra que a democracia de tal país está de fato funcionando.

Embora as questões econômicas não tenham sido as causas principais das insurreições e das revoltas da Primavera Árabe, não se pode negar que elas eram um dos antecedentes das revoltas, e isso é especialmente verdadeiro no que se refere à alta global do preço dos alimentos e da energia que se verificou na segunda metade de 2010.

Tal situação assemelhou-se à de 2008, e o efeito foi uma imediata escalada nos preços com um impacto direto nas populações mais pobres (Joffé, 2011). A economia da Tunísia crescia a uma taxa de 4.6\% em 2008 comparada com os $6.3 \%$ do ano anterior, e os efeitos da crise econômica mundial em 2008 continuaram a ser sentidos em 2009, quando a economia cresceu apenas 3.1\%. E justamente quando a economia estava dando sinais de recuperação, uma revolução eclodiu em resposta ao descontentamento expresso da população com taxas mais elevadas de desemprego e a inadequação das qualificações - refletindo em oportunidades desiguais - com preços elevados da comida, inflação, fortes medidas de austeridades do governo, falta de liberdade de expressão e más condições de vida (Chemingui \& Sánchez, 2011). Em 2010, a taxa anual de crescimento do PIB da Tunísia era de 3\%, e, em 2011, despencou para -1,9\% motivado pela revolta da população aliado a inflação alta de $5.7 \%$ e ao alto índice de desemprego (Ó.G., 2015). Já no ano seguinte, a taxa de crescimento do PIB foi de 3,9\%, que de acordo com o Ministério das Relações Exteriores (2018) a recuperação da economia deu-se por conta do crescimento dos gastos governamentais.

Com relação ao desempenho do Comércio Exterior da Tunísia, constata-se longos períodos de balança comercial negativa, acentuando-se a partir de 2010, em razão, principalmente, dos efeitos da crise política que passou pelo país, conforme dados do relatório elaborado pelo Ministério das Relações Exteriores (2016). Verifica-se que a governança e a estabilidade política demonstravam instabilidade em 2009, quando os índices apontavam queda na qualidade regulatória, eficiência do governo e instabilidade política, mesmo período onde aconteceram as quedas no PIB e na balança comercial da Tunísia. É possível observar-se a correlação da instabilidade política com a queda no desempenho econômico e da balança comercial tunisiana.

Apesar das elevadas tensões políticas, sociais e de insegurança, a economia da Tunísia tem preservado a estabilidade macroeconômica. Várias medidas de reformas, incluindo redução no subsídio e reforma nos setores públicos, foram realizadas, além da recapitalização dos três maiores bancos estatais, uma reforma bancária foi muito aguardada. Por outro 
lado, impedimentos institucionais à expansão econômica de base ampla permanecem profundamente enraizados. Enquanto privilégios políticos diminuíram substancialmente desde a revolução, o nível de percepção de corrupção continua sendo elevado inibindo ainda a confiança nas instituições políticas (The Heritage Foundation, 2016a).

Conforme sinalizado pelo World Banck Group (2012), a instabilidade política pode surgir pela preocupação com a empregabilidade, a desigualdade social, o aumento dos preços dos alimentos e os regimes políticos não democráticos, o que aconteceu com a Tunísia em 2011, com o descontentamento da população com a elevada taxa de desemprego, as medidas de austeridade do governo e os altos preços dos alimentos, conforme sinalizam Chemingui e Sánchez (2011).

\section{Ucrânia}

A crise política e social na Ucrânia iniciou em novembro de 2013, quando uma massa protestou contra o então presidente Viktor Yanukovych devido a sua decisão de abandonar um acordo com a União Europeia, que estreitaria os laços políticos e comerciais para fortalecer a aliança com a Rússia (Ramicone, et. al, 2014). Os mesmos autores salientam que os protestos tomaram proporções midiáticas internacionalmente quando o governo ucraniano autorizou ataques contra os manifestantes, resultando em pessoas presas, feridas e mortas.

Yanukovich, conforme reportagem do Jornal El País (2014), ignorou as exigências dos manifestantes e assinou com o presidente russo, Vladimir Putin, um acordo que incluía ajuda econômica e uma redução no preço do gás russo, porém o mesmo não ocorreu, pois, a companhia russa de gás anunciou aumento de 40\% no preço do produto fornecido à Ucrânia. Opositores instalaram-se no chamado Euromaidan e exigiram eleições antecipadas e uma reforma constitucional. Nesse intervalo, houve a criação de um novo governo Pró-EU e Anti-Rússia, que acirrou as tensões na península da Crimeia, de maioria russa, levando a uma escalada militar de Moscou na região.

A Ucrânia passa por um momento de recessão desde 2014, e os setores mais afetados são o metalúrgico e o minerador, cujos principais centros de produção estão no leste do país, imerso desde 2014 em um conflito armado entre Kiev e os separatistas Pró-Rússia (EXAME, 2015). O setor maquinário, cujo mercado de exportação principal é a Rússia, relatou uma forte queda de 21\% em 2014 (Adarov, et. al, 2015). Também sofreu o comércio no varejo lastrado por uma redução de renda da população, pela desvalorização da moeda nacional, pela redução dos salários e pela brusca alta das tarifas de energia e serviços públicos. Em 2014, quando a oposição europeísta derrubou o presidente Yunkovich após maciços protestos no centro de Kiev, a economia contraiu $7,5 \%$, e os preços subiram 24,9\%, conforme Revista EXAME (2015).

De acordo com a Fundação Heritage (2016b), o respeito pelo cumprimento da lei na Ucrânia ainda não foi estabelecido, e a falta de liberdade de investimento tem prejudicado a produtividade, incluindo o setor agrícola, que é muito importante para a país. O mercado ucraniano sofre de regulamentos ultrapassados, rígidos e inconsistentes, e a mão de obra tem diminuído devido à emigração e ao envelhecimento da população, e a prevalência de empresas estatais impede o desenvolvimento do setor privado (Heritage, 2016).

A instabilidade política instaurada na Ucrânia, ocorreu devido à incerteza pelo fato de o então presidente Yanukovych ter deixado de assinar um acordo com a EU para estreitar os laços com a Rússia. E essa incerteza, conforme Verdugo, Furceri e Guillaume (2013), gera um ambiente de instabilidade sociopolítica que tem impacto direto no crescimento da economia, principalmente no caso da Ucrânia, onde ocorreram fortes violências políticas.

A economia da Ucrânia crescia a uma média de $7.6 \%$ nos anos que antecederam a crise de 2008, ressentindo fortemente os efeitos da crise no ano seguinte, atingindo uma taxa de recessão de $-15.1 \%$ em 2009. Os dois anos seguintes foram de recuperação, alcançando 5.8\% em 2011, porém, a grande dependência das exportações de aço fez com que a economia mantivesse vulnerável a fatores externos, pela baixa procura externa e a lenta recuperação da economia internacional aliada a incerteza da. política macroeconômica ucraniana estimularam fraco desempenho, registrando em 2012 um crescimento de apenas $0.2 \%$, A crise política em 2013 veio a deteriorar ainda mais a situação econômica do país, entrando em seguidas taxas de crescimento negativas de $-0,03 \%$ em 2013, $-6.6 \%$ em 2014 e -9.8\% em 2015, conforme a Câmara de Comércio (2018). 
O desempenho da balança comercial vinha em queda desde 2009, mostra melhoras nos índices a partir de 2012.

\section{Paraguai}

A eleição de Lugo em 2008 encerrou com um ciclo de 61 anos do Partido Colorado conforme reportagem do Al Jazeera (2012). O impeachmentrelâmpago do então presidente do Paraguai, Fernando Lugo, em junho de 2012, promovido pela Câmara dos Deputados, gerou desconfiança internacional em relação ao Paraguai e uma resposta articulada dos países sul-americanos contra o país, desde a suspensão de investimentos e até a suspensão do Mercosul (BBC NEWS, 2012). Fernando Lugo foi desposto no dia 22 de junho por meio de um processo deflagrado em 20 de junho do mesmo ano, a pedido de um deputado do Partido Colorado. Lugo sempre teve problemas para governar o país desde o início do seu mandato em 2008. Ele não tinha maioria na Câmara e no Senado, com parlamentares sendo contrários a suas ações, especialmente na tentativa de resolver o complicado e antigo problema agrário do país.

Ele detinha como tema de campanha a redistribuição de terras e a reforma agrária, já que $80 \%$ das terras estão nas mãos de apenas $2 \%$ da população paraguaia, e, por nunca ter possuído maioria na Câmara de Deputados e no Senado, encontrou dificuldades para aprovar projetos que visavam à redistribuição de terras e à diminuição da desigualdade social. Isso fez com que sua popularidade caísse gradualmente e sua imagem ficasse cada vez mais denegrida, o que foi agravado pela manifestação dos sem-terra que deixaram 17 mortos. O presidente foi acusado de dar apoio aos manifestantes, que eram membros do grupo guerrilheiro Exército do Povo Paraguaio (Sírio, 2012).

As alegações do Senado para o impeachment foram de que Lugo apoiava a manifestação de jovens de esquerda no Comando de Engenharia das Formas Armadas, obrigava militares a se submeter às ordens de sem-terra, não tinha competência para combater atos de violência no país, apoiava as ações dos guerrilheiros do Exército do Povo e era o responsável pelo confronto entre policiais e camponeses, conforme Sírio (2012). A acusação descreveu os atos do governo de Lugo como negligente e irresponsável, e alegou mau desempenho das funções do cargo, por ele estar levando o Paraguai ao caos e à instabilidade política (Almeida \& Santana, 2014). A forma que o impeachment foi conduzido e a rapidez do processo gerou sérias desconfianças nos países vizinhos, tanto que o Paraguai foi suspenso do MERCOSUL, devido à alegação de que o país tinha descumprido a cláusula democrática reiterada pelos países do bloco, o denominado Protocolo de Montevidéu, em que consta que os países membros comprometem-se a proteger a democracia (Frizerra, 2013).

Estas instabilidades no país, acarretaram ainda na suspensão temporária dos blocos até que seja restaurada a normalidade democrática no país, pois os países sul-americanos da Unasul e do Mercosul recusaram-se a reconhecer legitimidade do impechment, alegando golpe de Estado. Em julho de 2013, o Mercosul aprovou o retorno do Paraguai ao bloco após a realização das eleições em abril de 2013, elegendo Horácio Cartes, e, em agosto de 2013, foi derrubada também a sua suspensão da Unsaul.

O Banco Mundial define a economia paraguaia como pequena e aberta, altamente dependente da produção agropecuária e do comércio exterior, conforme relatório do Ministério das Relações Exteriores (2015). Em termos relativos, sua moeda posiciona-se como uma das moedas mais estáveis frente ao dólar em comparação com outras moedas sul-americanas, e a inflação vem mantendo-se sob controle em níveis das metas estabelecidas pelo Banco Central do Paraguai. A economia paraguaia em 2010 apresentou alta, com recessão em 2011 e 2012. O retrocesso em 2012, segundo BBC NEWS (2012), ocorreu no momento em que o Paraguai estava politicamente suspenso e isolado do Mercosul e da Unasul, além da seca na produção de soja, um dos principais produtos de exportação do país. Em 2013, o Paraguai voltou a crescer fortemente após maior diversificação de suas exportações (CARMO, 2014).

O Paraguai possui uma economia pequena, mas relativamente aberta e vastos recursos naturais. A exportação de commodities tem sido muito importante para a economia paraguaia. No entanto, de acordo a Fundação Heritage (2016c), o surgimento de um setor privado mais vibrante permanece limitado pelas deficiências institucionais, e o progresso e a reforma do setor público têm sido desigual.

A liberdade de comércio do Paraguai é relativamente alta devido às barreiras tarifárias relativamente baixas. Já os ganhos são reduzidos em virtude da ausência de progresso em áreas como política, finanças e investimentos, o setor judicial 
carece de eficiência e independência política e a corrupção é percebida como generalizada (Heritage Foundation, 2016).

De acordo com a pesquisa documental apresentada, a instabilidade política no Paraguai deuse após um deputado do partido de oposição do governo de Lugo abrir processo para impedimento do presidente aliado à falta de apoio do Senado e da Câmara, uma vez que seu governo era minoria nos poderes legislativos. Badillo (2007) defendia que o modo para governar com estabilidade estava relacionado com a capacidade de junção de inciativas do poder legislativo com o poder executivo, uma vez que o então presidente Fernando Lugo possuía dificuldades de aprovar leis e iniciativas por possuir a minoria no poder legislativo, conforme Sírio (2012).

Por fim, os impactos dessa instabilidade política não foram tão sentidos como nos outros países relatados nesta pesquisa. Apesar da queda do PIB de 2011 para 2012 - início da instabilidade política -, a economia teve uma forte alta em 2013 que segundo Carmo (2014), está ligado a uma série de fatores como uma maior diversificação de suas exportações e uma maior abertura econômica, que inclui uma legislação tributária definida como 'simples', em relação a outros países. Apesar da suspensão de um pouco mais de um ano do Mercosul e da Unasul, o desempenho do comércio exterior paraguaio vem diminuindo ano a ano, desde 2011, o seu índice deficitário resultado de sua diversificação de exportações para países além do Mercosul.

\section{Brasil}

Na última década, o Brasil parecia estar à beira da expansão econômica, quando, em 2010, a economia do país cresceu a uma taxa de 7,5\%, seu maior desempenho em 24 anos. E o Brasil, a China, a India e a Rússia eram os países emergentes mais promissores do mundo (Segal, 2015). O Brasil vivia seu melhor momento na história do país. A crise internacional de 2008 não afetou muito o país e, apontado como uma das maiores forças econômicas, um país extremamente emergente, estava no centro das atenções no âmbito econômico mundial. Porém, desde 2013, a economia brasileira parou de crescer, após sucessões de medidas para estimular a economia que não deram certo (Villaverde, 2015).

O petróleo era o centro da estratégia brasileira, e isso deu à Petrobras um papel importante na influência da economia do Brasil, e em certo momento foi a sexta maior companhia do mundo por valor de mercado, o que respondeu a aproximadamente $10 \%$ do Produto Interno Bruto PIB, conforme reportagem de Segal (2015), para a The New York Times, divulgada pelo Jornal Estadão. Porém, em março de 2014, iniciou-se uma apuração de um suposto esquema de corrupção na Petrobras envolvendo diretores da estatal, grandes empreiteiras e políticos, denominado de Operação Lava Jato.

A Organização Não-Governamental Transparência Internacional, sediada em Berlim-Alemanha, promoveu uma pesquisa pela internet e verificou que o esquema de propinas da estatal brasileira, descoberta na Operação Lava Jato, é o segundo colocado como o maior caso de corrupção do mundo, conforme Macedo e Yoneya (2016), para o Jornal Estadão. Muitos críticos citam que a Operação Lava Jato deu início a uma das maiores instabilidades políticas do Brasil.

[...] Com a inflação bem acima da meta do Banco Central, as políticas tiveram uma mudança apropriada, para evitar uma crise econômica mais severa, diz o FMI. A instituição citou o aumento dos juros e o ajuste fiscal para conter pressões inflacionárias e estabilizar a trajetória da dívida pública. Ao mesmo tempo, surgiu uma crise política séria, de acordo com o Fundo (Valor Econômico, 2015, s/n).

No dia 02 de dezembro de 2015, o presidente da Câmara dos Deputados, Eduardo Cunha, deflagrou processo de impeachment da presidente da República, na justificativa de crime de responsabilidade por atraso em repasses aos bancos públicos (ocultando déficit nas contas), sem o aval do Legislativo, conforme a Revista EXAME (2016).

No dia 17 de abril de 2016, o impeachment foi aprovado no plenário da Câmara de Deputados. No dia 11 de maio, os Senadores da República votam pela admissibilidade do impeachment, e a presidente da República é afastada por até 180 dias. Michel Temer, vice-presidente da República, assume o cargo interinamente. Passados os 180 dias, o Senado Federal, no dia 31 de agosto aprovou o impedimento de Dilma Rousseff para a continuidade de seu mandato como Presidente da República por 61 votos a favor do impeachment e 20 contras. Desta maneira, Michel Temer assume definitivamente a presidência até 2018, fim do mandato. 
Causas e Impactos da Instabilidade Política na Perfomance do Comércio Internacional

Desde o início dos anos 2000, a economia brasileira tem crescido a um ritmo robusto, com um crescimento de 7,5\% em 2010. Em matéria publicada no jornal Valor Econômico, o FMI (2015) o recente escândalo de corrupção no Brasil e na Guatemala ilustra como as investigações sobre o desvio de dinheiro público podem desestabilizar o sistema político. Isso aumenta a incerteza para os agentes econômicos e tem um impacto negativo sobre as decisões de investimento e consumo. Os impactos diretos e indiretos da Operação Lava Jato na economia brasileira tiraram cerca de R\$ 142 bilhões na economia brasileira em 2015, o equivalente a uma retração de 2,5\% do PIB (Bittencourt; Vieira, 2016). A Lava Jato paralisou setores que tem peso grande nos investimentos totais da economia. Em seu conjunto, os investimentos de todas as empresas envolvidas na Lava Jato chegariam a quase $5 \%$ do PIB, em um país em que o nível total dos investimentos varia de 17 a 20\%, segundo Costas (2015).

Felter e Labrador (2018), dissertam que a economia brasileira já vinha sofrendo turbulências anteriores à Lava Jato, pensando inicialmente ser uma recessão temporária após sediar a Copa do Mundo, porém, com o agravamento da crise política, os níveis de investimento e de confiança do consumidor resultaram em um grande impacto na economia, levando a uma queda de $3.9 \%$ no PIB em 2015 e $3.6 \%$ no ano seguinte.

As empresas envolvidas no esquema de corrupção, algumas as maiores do país, de acordo com Felter e Labrador (2018) sofreram severas consequências financeiras. A Petrobrás, que em 2014 representava $14 \%$ do PIB brasileiro, perdeu aproximadamente US\$ 88 bilhões até meados de 2015. A petroleira e a Odebrecht venderam ativos na casa dos bilhões de dólares para pagamento de dívidas. Weller (2017) complemente que a fonte do escândalo, Petrobrás, responsável por 8.8\% do investimento nacional entre 2010 e 2014, cortou seus projetos em 24,5\% até 2019 o que reflete diretamente na economia brasileira, principalmente na cadeia produtiva.

De acordo com a análise documental, a instabilidade política brasileira teve seu início desencadeado pelo esquema de corrupção entre estatais brasileiras e empresas privadas descoberto pela Polícia Federal iniciado em 2014. Corrobora-se a teoria de Pessanha (2015) de que a corrupção pode resultar em uma instabilidade política, pois enfraquece as instituições democráticas reduzindo o desenvolvimento econômico, causando prejuízos para a economia e para a sociedade.

Em 2015 o PIB brasileiro registrou uma retração de $3.8 \%$ em relação a 2014, que já vinha em queda devido a crise mundial. Esta retração em 2015 foi a maior em 25 anos de acordo com o IBGE. Em matéria divulgado no portal eletrônico G1 (2016), constatouse que a queda do PIB foi influenciada pelo resultado negativo dos investimentos, pelo recuo no consumo das famílias e uma forte queda na indústria e serviços. Em complemento ao G1, o economista Pedro Raffy Vartanian acrescenta que a queda da indústria e do consumo das famílias está associada ao cenário no decorrer do ano passado, devido a baixa confiança e o cenário político turbulento.

Ressalta-se que, no ano de 2014 a balança comercial brasileira apresentou o primeiro saldo deficitário depois de 13 anos, sendo o mês de março de 2014 o inicio da apuração do esquema de corrupção o segundo pior mês da balança, e fevereiro o mês com o pior índice da balança comercial de 2014.

\section{CONSIDERAÇÕES FINAIS}

Instabilidades e crises políticas são tão sérias e importantes quanto as crises econômicas, uma vez que ambas estão relacionadas. Nos últimos anos, os profissionais de comércio exterior têm convivido frequentemente com essa realidade em diferentes países de diferentes continentes e atualmente os brasileiros também estão, novamente, vivendo essa realidade. Desta forma, a presente pesquisa possibilitou o estudo e a análise das causas e impactos que a instabilidade política gera na economia do país e no comércio exterior. Conclui-se que a instabilidade política ocorre de diferentes formas e motivos diversos, em cada país, podendo ser por golpe partidário, instabilidade econômica, violência, desigualdade social, mas sempre representam uma repercussão relevante no comércio internacional, mas em configurações diferentes em cada país.

Por meio da pesquisa bibliográfica, foi possível validar as duas principais teorias, a da globalização frente aos Estados e a teoria e estudo do que é e o que causa a instabilidade política sob diferentes óticas e de que forma se aplica em instabilidades políticas ocorridas recentemente. Também foi possível realizar a sua interpretação, com base em 
evidências que emergiram a partir da pesquisa documental, do processo interacional e relacional entre a instabilidade política e comércio internacional, em cada um dos países analisados, facultando a análise à luz da revisão teórica.

Os profissionais e estudiosos da área de comércio exterior têm presenciado mudanças drásticas no ramo, como a saída do Reino Unido da União Europeia, a nova onda de imigração dos cidadãos da Ásia Ocidental para a Europa e as recorrentes crises políticas que ocorrem principalmente na América Latina. Pela dificuldade de vislumbrar uma solução, a curto prazo, para as causas de instabilidade política, que envolvem, entre outros, principalmente, fatores culturais e o passado histórico de cada país, torna-se relevante para os profissionais que atuam no comércio internacional, desenvolver a capacidade de adaptar o modelo de negócio para lidar com os riscos,

\section{REFERÊNCIAS}

Adarov, A., Astrov, V., Havlik, P., Hunya, G., Landesmann, M., \& Podkaminer, L. (2015). How to Stabilise the Economy of Ukraine. The Vienna Institute for International Economic Studies (wiiw), April.

Ahmed, M. U., \& Pulok, M. H. (2013). The role of political stability on economic performance: the case of Bangladesh. Journal of Economic Cooperation \& Development, 34(3), 61.

Al Jazeera. (2012). Paraguay: Impeachment or political coup. Disponível em: $<$ https://www.aljazeera.com/programmes/insidesto ryamericas/2012/06/20126265451105780.html>.

Acesso em: 07 março 2018.

Almeida, W., \& Santana, H. L. (2014). Integração e democracia: Os interesses políticos locais que distorcem o direito internacional e a crise política resultante da suspensão do Paraguai do Mercosul.Revista de Informação Legislativa, v. 51, n. 203, p. 91-110, jul./set.

Badillo, M. J. (2007). Gobernando sin mayorías parlamentarias en América Latina. Opinião Pública, 13(1), 148-184.

BBC News. (2011). Entenda a crise na Tunísia. Disponível em: <http://www.bbc.com/portuguese /noticias/2011/01/110114_tunisia_qa_rc.shtml>. Acesso em 17 de ago. 2016. que são inevitáveis. Por isso, torna-se primordial, ao menos, compreender as causas e consequência desses fenômenos, uma vez que não interferem somente na vida de uma instituição pública e/ou privada, mas sim, repercutem, de forma relevante, na sociedade como um todo.

É válido também mencionar as limitações da pesquisa, com destaque para ausência de informações econômicas no tocante ao impacto do referido fenômeno na performance do comércio internacional de cada país, por não ser o objetivo deste ensaio teórico. Esta, por sinal, representa a recomendação de estudos futuros. Apesar da referida limitação os autores entendem que o trabalho alcançou o objetivo que foi o de analisar o impacto da instabilidade política sobre o comércio internacional, de forma exploratória, com base em dados secundários.

BBB News. (2012). Paraguai será único país na América Latina com recessão em 2012. Disponível em: <https://www.bbc.com/portuguese/noticias/2012/11/ 121127_paraguai_recessao_dg $>$. Acesso em $17 \mathrm{dez}$ 2018.

Bittencourt, A., \& Vieira, C. (2016). "O efeito da Lava Jato no PIB se confirmou" diz Gesner Oliveira. Valor Econômico. Disponível em: http://www.valor.com.br/valor-investe/casa-dascaldeiras/4672327/o-efeito-da-lava-jato-no-pib-seconfirmou-diz-gesner-olivei>. Acesso em 13 de jun 2018.

Camara de Comercio e Industria Portuguesa. (2018). Ucrânia: Enquadramento Económico. Disponível em: <https://www.ccip.pt/pt/newsletterinternacional/897-ucrania-enquadramentoeconomico>. Acesso em 05 de jun. 2018.

Campos, L., \& Canavezes, S. (2007). Introdução à Globalização. Instituto Bento Jesus Caraça: Abril.

Carmo, M. (2014). Paraguai descola do Brasil e tem $3^{\circ}$ maior crescimento do mundo em 2013. Bbc News. Disponível em: < http://www.bbc.com/portuguese/noticias/2014/01/ 140119_paraguai_econ omia_pai_mc $>$. Acesso em 09 março 2018.

Chasquetti, d. (2001), Democracia, Multipartidarismo y Coaliciones en América Latina: Evaluando la Difícil Combinación. in J. Lanzaro (org.), Tipos de Presidencialismo 
Causas e Impactos da Instabilidade Política na Perfomance do Comércio Internacional

Cheibub, J. A. (2002). Minority governments, deadlock situations, and the survival of presidential democracies. Comparative political studies, 35(3), 284-312.

Cervo, A. L., Bervian, P. A., \& Silva, R. (2007). Metodologia científica. 6. ed. São Paulo, SP: Pearson Prentice Hall.

Chemingui, M. A., \& Sánchez, M. V. (2011). The Republic of Tunisia. United Nations Department for Social and Economic Affairs.

Chomiak, L. (2014). The richness of Tunisia's new politics. Disponível em: <https://www.washingtonpost.com/blogs/monkeycage/wp/2014/10/29/the-richness-of-tunisias-newpolitics/>. Acesso 07 março de 2018.

Clark, G. (2008). Política econômica e Estado. Estudos avançados, 22(62), 207-217.

Coelho, B. D., \& Oliveira J., (2016). A internacionalização de empresas na agenda governamental contemporânea de desenvolvimento: reflexões críticas e analíticas para os negócios internacionais. Cadernos EBAPE. BR, 14.

Costas, R. Escândalo da Petrobras engoliu 2,5\% da economia de 2015. (2015) BBC Brasil. Disponível em: <http://www.bbc.com/portuguese/noticias/2015/12 /151201 lavajato ru> . Acesso em 26 ago. 2016.

Drazen, A. (2000). The political business cycle after 25 years. NBER macroeconomics annual, 15, 75-117.

Exame. (2015) Economia ucraniana se contrairá 12\% este ano, indica BM. Disponível em: <http://exame.abril.com.br/economia/noticias/econ omia-ucraniana-se-contraira-12-este-ano-indicabm>. Acesso em: 09 março 2018.

Exame. (2016) A linha do tempo do impeachment de Dilma. Disponível em: <http://exame.abril.com.br/brasil/noticias/a-linhado-tempo-do-impeachment-de-dilma-ate-agora>. Acesso em 21 ago. 2016.

Felter, C., \& Labrador, R. C. (2018). Brazil's Corruption Fallout. Council on Forgein Relations. Disponível em:

$<$ https://www.cfr.org/backgrounder/brazilscorruption-fallout>. Acesso em 17 de jun 2018.

Fundo Monetário Internacional. (2016). Corruption: Costs and Mitigating Strategies. 2016. Disponível

em: <http://www.imf.org/external/pubs/ft/sdn/2016/sd n1605.pdf>. Acesso em 26 ago, 2016.

Frizzera, G. (2013). A suspensão do Paraguai no MERCOSUL: problema interno, solução externa. Conjuntura Global, 2(3), p. 156-164.

Fronzaglia, M. L. (2011). Políticas Públicas Internacionais: o caso do Processo de Bolonha. $310 \mathrm{f}$. Tese (Doutorado em Ciências Políticas) - UNICAMP, Campinas, SP.

G1. (2013). Entenda a crise na Ucrânia. Disponível em: <http://g1.globo.com/ mundo/noticia/2013/12/entenda-os-protestos-naucrania.html>. Acesso em 17 ago. 2016.

G1. (2013). UNASUL anula suspensão do Paraguai. Disponível em: <http://g1.globo.com/ mundo/noticia/2013/08/suspensao-do-paraguai-naunasul-e-anulada.html>. Accesso em: 24 ago. 2016.

G1. (2016). Indústria recua 2,5\%, a maior queda para fevereiro da série histórica. Disponível em: < http://g1.globo.com/economia/noticia/2016/04/pro ducao-da-industria-recua-25-em-fevereiro.html>. Acesso em: 10 jul 2018.

Gil, A. C. (2008). Métodos e técnicas de pesquisa social. 6. ed. Ediitora Atlas SA.

Hinds, R. (2014). Conflict analysis of Tunisia. GSDRC, University of Birmingham.

Joffé, G. (2011). A Primavera Árabe no Norte da África: as origens e perspectivas de futuro. Relações Internacionais, n. 30, Lisboa jun.

Jornal el País. As razões da crise ucraniana. 2014. Disponível em: <https://brasil.elpais.com/brasil/2014/03/03/interna cional/1393862263 932760.html>. Acesso em 17 dezembro 2018.

Köche, J. C. (2011). Fundamentos de metodologia científica: teoria da ciência e iniciação à pesquisa. Editora Vozes, Petrópolis.

Lins, H. N. (2013). Globalização, empresas transnacionais e Estado nacional: ensaio sobre questões candentes da atualidade considerando o setor agroalimentar e o Brasil.

Macedo, F., \& Yoneya, F. (2016). Petrobras é o segundo maior escândalo de corrupção do mundo, aponta Transparência Internacional. Disponível em: <http://politica.estadao.com.br/blogs/faustomacedo/petrobras-e-o-segundo-maior-escandalo- 
de-corrupcao-do-mundo-aponta-transparenciainternacional/>. Acesso em: 9 março 2018.

Marconi, M. A., \& Lakatos, E. M. (2011). Metodologia científica. 6. ed., rev. ampl. São Paulo, SP: Atlas.

Mariano, K. P. (2007). Globalização, integração e o estado. Lua Nova, 123-168.

Ministério Das Relações Exteriores, Departamento De Promoção Comercial E Investimentos E Divisão De Inteligência Comercial. Guia de Negócios: Tunísia. Disponível em: $<$ https://investexportbrasil.dpr.gov.br/arquivos/Publica coes/ComoExportar/GNTunisia.pdf>. Acesso em: 09 março 2018.

Ministério das Relações Exteriores, Departamento de Promoção Comercial e Investimentos e Divisão de Inteligência Comercial. Ucrânia: Comércio Exterior. Disponível

em: $<$ http://www.investexportbrasil.gov.br/sites/default/fil es/publicacoes/indicadoresEconomicos/INDUcrania.pd f>. Acesso em: 09 março 2018.

Ministério das Relações Exteriores, Departamento de Promoção Comercial e Investimentos e Divisão de Inteligência Comercial. Paraguai: Comércio Exterior. Disponível em: <http://www.investexportbrasil.gov.br/sites/default/fil es/publicacoes/indicadoresEconomicos/INDParaguai.p df>. Acesso em: 09 março 2018.

Ministério das Relações Exteriores, Departamento de Promoção Comercial e Investimentos e Divisão de Inteligência Comercial. Brasil: Comércio Exterior. Disponível em: $<$ https://investexportbrasil.dpr.gov.br/arquivos/Indic adoresEconomicos/web/index.html?a=INDBrasil\&p= 00001 >. Acesso em: 09 março 2018.

Moura, D. F., Filipe, J. A., Ferreira, M. A. M., Coleho, M., \&Pedro, I. (2011). An Analysis of the Political Risks Environment in American Developing Countries. Lisboa: International Journal of Academic Research, 3(4).

Negretto, G. L. (2004). Minority Presidents and types of government in Latin America. Centro de Investigación y Docencia Económicas.

$$
\begin{array}{ccc}
\text { Ó.G. (2015). Desemprego e terror corroem a Tunísia. } \\
\text { EL PAís. }
\end{array}
$$
<https://brasil.elpais.com/brasil/2015/03/21/internaci onal/1426971014_091993.html> Acesso em 18 de jun de 2018 .
Pereira, A. K. B. (2015). Mudança Social e Instabilidade Política: uma leitura da obra de Samuel Huntigton. In.: III Semana de Ciência Política Universidade Federal de São Carlos, São Paulo.

Pessanha, M. V. M. (2015). Crise institucional, desenvolvimento econômico e instabilidade política: como a corrupção enfraquece as instituições democráticas brasileiras. Disponível em: $<$ https://jus.com.br/artigos/37734/crise-institucionaldesenvolvimento-economico-e-instabilidade-politicacomo-a-corrupcao-enfraquece-as-instituicoesdemocraticas-brasileiras >. Acesso em: 09 março 2018.

Ramicone, A., Rocca, P., Gisser, S., \& Metzger, J. (2014). The Ukrainian Crisis: A Disputed Past and Present. Harvard Policy Brief.

Segal, D. (2015). O escândalo da Petrobras e o sonho perdido dos brasileiros. Disponível em:< http://economia.estadao.com.br/noticias/geral,esca ndalo-da-petrobras-deixa-brasileiros-lamentandoum-sonho-perdido,1741265>. Acesso: 09 março 2018.

Sírio, A. O. (2012). O Impeachment de Lugo: Uma mistura de interesses, oportunismo e valos discutíveis. Disponível:<https://pucminasconjuntura.wordpress. com/2012/09/28/o-impeachment-de-lugo-umamistura-de-interesses-oportunismo-e-valoresdiscutiveis/>. Conjuntura Internacional. PUC Minas. Acesso 09 março 2018.

Souza, A. L. C. F. (2009). Instabilidade política e quedas presidenciais na América do Sul: causas e consequências. Disponível em:< paperroom.ipsa.org/papers/paper_2290.pdf>. Congresso Mundial de Ciência Política - IPSA, Santiago, Chile. Acesso em: 09 março 2018.

The Heritage Foudation. (2016a) Index Economic Freedom. Tunisia. Disponível em: < https://www.heritage.org/index/country/tunisia>. Acesso em: 09 março 2018.

The Heritage Foudation. (2016b). Index Economic Freedom. Ukraine. Disponível Em: <Http://Www.Heritage.Org/Index/Country/Ukraine> . Acesso em: 09 março 2018.

The Heritage Foudation. (2016c). Index Economic Freedom. Paraguay. Disponível em: <http://www.heritage.org/index/country/paraguay>. Acesso em: 09 março 2018. 
The World Bank. (2012). Tunisia. Disponível em: <https://data.worldbank.org/country/tunisia>. Acesso em: 09 março 2018.

Torres, J. B. (2006). Oportunidades e riscos no comércio internacional para as empresas exportadores pernambucanas. 228 f. Dissertação (Mestrado em Economia) - Universidade Federal de Pernambuco, RE.

Valor Econômico. (2015). FMI: Corrupção e crise política afundaram recessão no Brasil. Disponível em: <http://www.valor.com.br/brasil/4260976/fmicorrupcao-e-crise-politica-aprofundaram-recessao-nobrasil>. Acesso em: 09 março 2018.

Villaverde, J. O PT e o governo de Dilma em 2015. ESTADÃO. Disponível em: < https://economia.estadao.com.br/blogs/joaovillaverde/o-pt-e-o-governo-dilma-em-2015/>. Acesso em 10 jul 2018.

Verdugo, L. E. B., Furceri, D., \& Guillaume, D. (2013). The Dynamic Effect of Social and Political
Instability on Output: The Role of Reforms. International Monetary Fund. Disponível em: < https://www.imf.org/external/pubs/ft/wp/2013/wp 1391.pdf >. Acesso em: 09 março 2018.

Vergara, S. C. (2016). Projetos e relatórios de pesquisa em administração. 16. ed. Rio de Janeiro: Atlas.

Weller, L. (2017). A Lava Jato e o tombo do investimento. Escola de Economia de São Paulo Fundação Getúlio Vargas. Disponível em: <http://eesp.fgv.br/noticias/lava-jato-e-o-tombo-doinvestimento>. Acesso em 06 de jun 2018.

World Bank Group. (2012). World Investment Trends and Corporate Perspectives the Political Risk Insurance Industr Breach of Contract. Washington: Multilateral Investment Guarantee Agency. Disponível em: < www.miga.org/sites/default/files/archive/.../WIPR13 .pdf>. Acesso em 12 dez 2018.

\section{SOBRE OS AUTORES:}

- Thamires Stoffel - Bacharel em Comércio Exterior pela Universidade Feevale, Rio Grande do Sul, (Brasil). E-mail: thamires.stoffel@gmail.com Orcid id: http://orcid.org/0000-0003-4478-0312

- Vanessa Theis - Doutora em Qualidade Ambiental pela Universidade Feevale. Rio Grande do Sul, (Brasil). E-mail: vanessat@feevale.br Orcid id: http://orcid.org/0000-0002-5100-7574

- Dusan Schreiber - Doutor em Administração pela Universidade Federal do Rio Grande do Sul - UFRGS, Rio Grande do Sul, (Brasil). E-mail: dusan@feevale.br Orcid id: https://orcid.org/0000-0003-4258-4780 


\section{CAUSES AND IMPACTS OF POLICY INSTABILITY IN THE PERFORMANCE OF INTERNATIONAL TRADE}

Thamires Stoffel, Vanessa Theis \& Dusan Schreiber Universidade FEEVALE, Rio Grande do Sul, (Brasil)

ARTICLE DETAILS
Article history:
Received: june 92018
Accepted: october 302018
Available online January: 01th 2019
Double Blind Review System
Scientifc Editor
Ilan Avrichir
Keywords:
Political Instability
Foreign trade
Globalization
Governments
Political Crisis

\section{ABSTRACT}

This research presents a reflective study about possible causes and the impacts of political instability on the performance of international trade. In a theoretical essay format, this article is based on a theoretical review of authors discussing globalization and its reflections on States, and on the specificities that characterize political instability. In sequence, with the purpose of evidencing the elements that were identified from the theoretical revision, a study based on a documentary survey was carried out, detailing the situations and context of countries that have passed or recently experienced political instability: Tunisia, Ukraine, Paraguay and Brazil, in order to analyze the impacts that the political instability causes in the International Trade of these countries.

(C) 2018 Internext | ESPM. All rights reserved!

Para citar este artigo:

Stoffel, T., Theis, V., \& Schreiber, D. (2019). Causas e Impactos da Instabilidade Política na Perfomance do Comércio Internacional.Revista Eletrônica de Negócios Internacionais, 14(1), 31-44. doi:https://doi.org/10.18568/internext.v14i1.445 